\title{
Improving estimates of the burden of severe acute malnutrition and predictions of caseload for programs treating severe acute malnutrition: experiences from Nigeria
}

\author{
Assaye Bulti ${ }^{1 *}$ (D) André Briend ${ }^{2,3}$, Nancy M. Dale², Arjan De Wagt ${ }^{1}$, Faraja Chiwile ${ }^{1}$, Stanley Chitekwe ${ }^{4}$, \\ Chris Isokpunwu ${ }^{5}$ and Mark Myatt ${ }^{6}$
}

\begin{abstract}
Background: The burden of severe acute malnutrition (SAM) is estimated using unadjusted prevalence estimates. SAM is an acute condition and many children with SAM will either recover or die within a few weeks. Estimating SAM burden using unadjusted prevalence estimates results in significant underestimation. This has a negative impact on allocation of resources for the prevention and treatment of SAM. A simple method for adjusting prevalence estimates intended to improve the accuracy of burden estimates and caseload predictions has been proposed. This method employs an incidence correction factor. Application of this method using the globally recommended incidence correction factor has led to programs underestimating burden and caseload in some settings.

Methods: A method for estimating a locally appropriate incidence correction factor from prevalence, population size, program caseload, and program coverage was developed and tested using data from the Nigerian national SAM treatment program.

Results: Applying the developed method resulted in errors in caseload prediction of about $10 \%$. This is a considerable improvement upon the current method, which resulted in a 79.5\% underestimate. Methods for improving the precision of estimates are proposed.

Conclusions: It is possible to considerably improve predictions of caseload by applying a simple model to data that are readily available to program managers. This implies that more accurate estimates of burden may also be made using the same methods and data.
\end{abstract}

Keywords: Severe acute malnutrition, Burden, Caseload, Prevalence, Incidence, Nigeria

\section{Background}

A child with severe acute malnutrition (SAM) has a high risk of near term mortality $[1,2]$. It has been estimated that SAM affected more than 16 million children globally in 2016 [3]. This figure is based on prevalence estimates from cross-sectional surveys. SAM is an acute condition

\footnotetext{
* Correspondence: bulti.ta@gmail.com

'United Nations Children's Fund (UNICEF), Abuja, Nigeria

Full list of author information is available at the end of the article
}

and many children with SAM will either recover or die within a few weeks. Estimating the number of SAM cases present in a population over a given period of time, the "SAM burden", using unadjusted prevalence estimates is likely, therefore, to miss many new (incident) cases and significantly underestimate the SAM burden [4]. A recent estimate of the annual global SAM burden that attempts to account for incident cases suggests that 110 million cases per year might be a more accurate estimate [5]. Poor estimates of SAM burden are a problem for program managers at all levels. Underestimation has a negative 
impact on the prioritization of resource allocation for the prevention and treatment of SAM both globally and locally [6].

Burden is the sum of prevalent cases at the start of a period and incident cases that arise during that period. The number of prevalent cases in a population at a given point in time can be estimated using a combination of a prevalence estimate from a cross-sectional survey and population data. This information is usually already available to program managers. Incidence is more complicated and more expensive to estimate.

The relationship between incidence and prevalence is frequently described using a "bathtub" metaphor [7]. In this model the flow of water into the bathtub is analogous to incidence, the level of the water in the bathtub represents prevalence, and the flow of water out of the bathtub through the drain represents recovery and mortality. Incidence in relation to prevalence depends, to a large extent, upon the average duration of illness (see Fig. 1).

The simple relationship between prevalence, incidence, and duration of illness makes it possible to create a simple mathematical model that allows the estimation of burden using prevalence and population estimates together with other data (e.g. program coverage and program caseloads) that will usually be available to program managers.

The Community Management of Acute Malnutrition (CMAM) Forum has proposed a simple method to estimate SAM burden and predict the number of cases that a program will treat over a given planning period [8]. The number of prevalent cases present in a population at the time of a prevalence survey is estimated as the product of prevalence and population size:

\section{Estimated number of prevalent cases $=N P$}

where:

$N$ is the size of the population of interest

$P$ is the prevalence of the condition of interest

The population burden $(B)$ consists of both prevalent cases and new (incident) cases that are expected to occur in the program area over a given planning period:

$$
\begin{aligned}
\text { Burden }(B)= & \text { Estimated number of prevalent cases } \\
& + \text { Expected number of incident cases }
\end{aligned}
$$

The expected number of incident cases can be estimated using:

\section{Expected numer of incident cases $=$ NPK}

where $K$ is a correction factor [9] calculated as:

$$
K=\frac{\text { Duration of planning period }}{\text { Average duration of a disease episode }}
$$

This allows the population burden $(B)$ to be estimated:

$$
\begin{aligned}
B= & \text { Estimated number of prevalent cases } \\
& + \text { Expected number of incident cases } \\
B= & N P+N P K \\
B= & N P(1+K)
\end{aligned}
$$

The population burden $(B)$ can be used to predict the number of cases that a program will treat over the planning period $(L)$ using an estimate of program coverage $(C)$ :

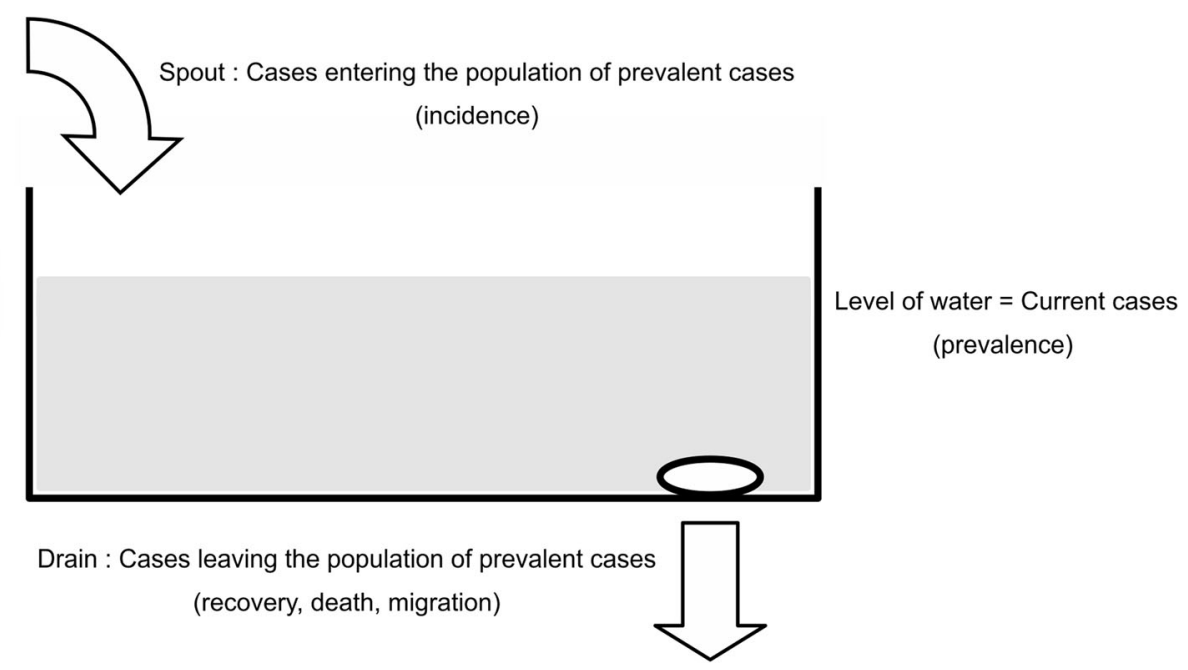

Fig. 1 The "bathtub" metaphor for the relationship between incidence and prevalence. The rate at which cases leave the population depends upon the average duration of illness 
Expected program caseload $(L)$

$=$ Expected coverage $(C) \times$ Population burden $(B)$

$L=C N P(1+K)$

All of the terms in this estimator are subject to uncertainty.

Uncertainty regarding coverage $(C)$ and prevalence $(P)$ is usually quantifiable and is quantified by confidence intervals or credible intervals on point estimates. The prevalence of severe acute malnutrition (SAM) is often estimated with poor relative precision. For example, the commonly used Standardised Monitoring and Assessment of Relief and Transitions (SMART) prevalence surveys typically have effective sample sizes (i.e. the sample size after accounting for survey design effects) between $n=300$ and $n=400$ [10]. An effective sample size of $n=400$ yields an exact $95 \%$ confidence interval of [0.55\%; $3.24 \%]$ on a $1.50 \%$ point estimate of SAM prevalence [11]. The relative precision of this estimate is:

$$
\text { Relative precision }(\%)=\frac{3.24-0.55}{1.50} \times 100=179.3 \%
$$

Coverage is typically estimated with a precision of about $\pm 10 \%$ on a $50 \%$ estimate [12]. This is a $40 \%$ relative precision.

Useful accuracy of population estimates can be achieved by correcting census data to account for population growth and migration. It can often be assumed that the population is estimated with little or no error. This may not, however, be the case in emergencies in which there is considerable and ongoing population movement and / or high levels of mortality.

Caseload $(L)$ is a simple count of program admissions. This data is collected and reported on a routine basis and can usually be assumed to be measured with little or no error.

There is considerable uncertainty about the value of the incidence correction factor $(K)$. The average duration of an untreated SAM episode that is currently being used globally is 7.5 months. This is based on data from two cohort studies and provides an incidence correction factor $(K)$ of 1.6 for a one-year planning period [13]. It was assumed that this value of $K$ would apply in all contexts. Governments, United Nations agencies, non-governmental organizations (NGOs), and other SAM treatment program implementing partners have, in the absence of other evidence, been using this value of $K$ to estimate the burden and expected caseload and to advocate for resources to treat children with SAM. Reports from SAM treatment programs suggest that the use of $K=1.6$ has led to programs underestimating caseload in some West African settings. Recent work indicates that a single value of $K$ for use globally may not be useful (see Table 1) [6, 14-16].
Data from the Nigerian Community-based Management of Acute Malnutrition (CMAM) program from 2014 and 2015 are presented in this article. This program started operations in 2009 and has treated between 300 thousand and 500 thousand SAM cases each year. During the course of implementation it was recognized that the use of $K=1.6$ had led to considerable underestimation of SAM burden and program caseload. Given the public health and security situation in Nigeria it is anticipated that the $\mathrm{Ni}$ gerian CMAM program will run for many years and accurate estimates of expected caseloads will be required to secure adequate continued funding.

This article presents a method to adjust or calibrate the value of $K$ using the population of the program area, the number of program admissions, estimates of program coverage, and estimates of the prevalence of SAM in order to provide more accurate estimates of burden and expected caseload during program implementation. The method is illustrated using data from the Nigerian CMAM program. The revised estimate of $K$ may also be useful to predict SAM burden and caseload from prevalence surveys in similar settings.

\section{Methods}

The caseload estimation formula:

$$
L=C N P(1+K)
$$

can be rearranged to find $K$ given the other terms:

$$
\begin{aligned}
& L=C N P(1+K) \\
& 1+K=\frac{L}{C N P} \\
& K=\frac{L}{C N P}-1
\end{aligned}
$$

A suitable value for $K$ can be found by substituting known values for $L, C, N$, and $P$ with $L$ being the $o b$ served program caseload (i.e. the number of admissions).

The method outlined here assumes that both population $(N)$ and caseload $(L)$ are measured with little or no error although the method can be easily extended to accommodate uncertainty in these terms. The principal sources of uncertainty in this analysis are, therefore, prevalence $(P)$ and coverage $(C)$. This can lead to considerable uncertainty in their product $(P C)$ used in the estimator (Additional file 1).

An approximate $95 \%$ confidence interval for the product of two proportions (i.e. prevalence $(P)$ and coverage (C) in this application):

$$
\widehat{\theta}=P \times C
$$

is given by: 
Table 1 Values of incidence correction factors $(K)$ found in recent studies ${ }^{a}$

\begin{tabular}{|c|c|c|c|c|c|c|c|}
\hline Country & Year(s) & $K^{b}$ & SAM case definition $(s)^{c}$ & $\begin{array}{l}\text { W/H } \\
\text { Reference }^{c}\end{array}$ & Data Source(s) & Method & Source \\
\hline Niger & $2010-2013$ & $4.30-9.50$ & $\begin{array}{l}\text { W/H }<-3 \text { z-scores or } \\
\text { MUAC }<115 \mathrm{~mm} \text { or bi- } \\
\text { lateral pitting edema }\end{array}$ & WGS & $\begin{array}{l}\text { Surveillance system (weekly) } \\
\text { Routine program data (weekly) } \\
\text { Routine program data (monthly) }\end{array}$ & $\begin{array}{l}\text { Simple mathematical } \\
\text { models }\end{array}$ & $\begin{array}{l}\text { Deconinck } \\
\text { et al., } 2016 \\
{[14]}\end{array}$ \\
\hline Niger & 2006-2007 & $5.37-11.78$ & $\begin{array}{l}\text { W/H }<-3 \text { z-scores or } \\
\text { MUAC }<115 \mathrm{~mm} \text { or bi- } \\
\text { lateral pitting edema }\end{array}$ & WGS & Community cohort (monthly) & $\begin{array}{l}\text { Compartmental model } \\
\text { to estimate mean } \\
\text { duration of SAM } \\
\text { episodes }\end{array}$ & $\begin{array}{l}\text { Isanaka et } \\
\text { al., } 2011 \text { [6] }\end{array}$ \\
\hline Mali & 2010-2013 & $2.10-2.50$ & $\begin{array}{l}\text { W/H }<-3 \text { z-scores or } \\
\text { MUAC }<115 \mathrm{~mm} \text { or bi- } \\
\text { lateral pitting edema }\end{array}$ & WGS & $\begin{array}{l}\text { Community cohort (quarterly) } \\
\text { Surveys (occasional) }\end{array}$ & $\begin{array}{l}\text { Simple mathematical } \\
\text { models }\end{array}$ & $\begin{array}{l}\text { Isanaka et } \\
\text { al., 2016 } \\
{[15]}\end{array}$ \\
\hline Niger & 2010-2011 & $5.00-8.10$ & $\begin{array}{l}\text { W/H }<-3 \text { z-scores or } \\
\text { bilateral pitting edema }\end{array}$ & WGS & $\begin{array}{l}\text { Community cohort (monthly) } \\
\text { Surveys (monthly) }\end{array}$ & $\begin{array}{l}\text { Simple mathematical } \\
\text { models }\end{array}$ & \\
\hline Burkina Faso & $2009-2010$ & $7.30-17.00$ & $\begin{array}{l}\text { MUAC <110 mm } \\
\text { (prevalence) MUAC } \\
<120 \mathrm{~mm} \text { (incidence) }\end{array}$ & WGS & $\begin{array}{l}\text { Surveys (annual) Routine } \\
\text { program data (monthly) }\end{array}$ & $\begin{array}{l}\text { Simple mathematical } \\
\text { models }\end{array}$ & \\
\hline Various $^{d}$ & 2005-2009 & 11.21 & W/H $<70 \%$ of median & $\mathrm{NCHS}$ & $\begin{array}{l}\text { Surveys Caseloads for } 5 \text { months } \\
\text { after survey }\end{array}$ & Linear regression & $\begin{array}{l}\text { Dale et al., } \\
2017[16]\end{array}$ \\
\hline
\end{tabular}

${ }^{\mathrm{a} A}$ range of methods and data sources were used (surveillance systems, workload returns, cohort studies, repeated cross-sectional surveys, compartmental models, and regression of observed caseload against prevalence) were used to estimate the incidence correction factors ( $K$ ). Refer to the original articles for details

${ }^{\mathrm{b}} \mathrm{A}$ range of values (i.e. from different methods, data sources, settings, and case-definitions for severe acute malnutrition) is given when available

'SAM = severe acute malnutrition, $\mathrm{W} / \mathrm{H}=$ weight-for-height, $\mathrm{MUAC}=$ mid-upper-arm circumference, WGS $=$ World Health Organization child growth standards,

$\mathrm{NCHS}=$ National Center for Health Statistics child growth reference

${ }^{d} 24$ datasets (surveys and program admissions) from DRC (8), Burundi (2), Somalia (2), Sudan (7), Myanmar (2), and Niger (3). The incidence correction factor ( $K$ ) given in the table is for pooled data assuming coverage $(C)$ of $38 \%$ (from Rogers et al., 2015). Considerable variation in $K$ between settings was observed

$$
\widehat{\theta} \times e^{ \pm 1.96 \times S E(\log \hat{\theta})}
$$

where:

$$
S E(\log \hat{\theta})=\sqrt{\frac{1-P}{n_{P} \times P}+\frac{1-C}{n_{C} \times C}}
$$

and $n_{P}$ and $n_{C}$ are the sample sizes used to estimate prevalence $(P)$ and coverage $(C)$ respectively [17]. This formula is not immediately applicable to the sorts of data likely to be available to program managers because the effective sample sizes used to estimate both prevalence and coverage $\left(n_{P}\right.$ and $\left.n_{C}\right)$ will differ from reported sample sizes due to design effects introduced by the use of complex samples and / or the use of prior information $[12,18,19]$.

Prevalence is usually estimated using surveys employing complex sample designs. The prevalence estimates used in this report were made by combining results from several cross-sectional household surveys that used a two-stage cluster sample design representative at the state level following the SMART methodology [10, 20, 21].

Coverage of CMAM programs is often estimated using spatially stratified samples [12, 22-24]. Semi-Quantitative Evaluation of Access and Coverage (SQUEAC) coverage assessments use a Bayesian beta-binomial conjugate analysis in which the conjugate prior contains information that contributes "pseudo-observations" to the analysis [12, 19].
The effective sample size associated with the estimate of a proportion can be calculated from the reported point estimate $(p)$ and its associated upper and lower 95\% confidence limits ( $U C L$ and $L C L$ ).

Variance $(V A R)$ is calculated as:

$$
V A R=\left(\frac{U C L-L C L}{2 \times 1.96}\right)^{2}
$$

The effective sample size $\left(n_{\text {effective }}\right)$ is calculated as:

$$
n_{\text {effective }}=\frac{p(1-p)}{V A R}
$$

rounded to the nearest whole number.

This calculation is performed to find both $n_{P}$ and $n_{C}$ before calculating $S E(\log \hat{\theta})$.

We used the approach outlined above to find a suitable value for $K$ for the Nigerian CMAM program. Data relating to program admissions (i.e. caseload) in 2014 and 2015 were taken from routine program monitoring reports. Population estimates were made using data from the 2006 Nigerian Census corrected for population growth and migration [25]. Prevalence estimates for SAM were available for 2014 and 2015 [20, 21]. An estimate of program coverage was available from a wide-area Simplified Lot-qualityassurance Evaluation of Access and Coverage (SLEAC) survey completed in early 2014 [12, 26, 27]. The reported coverage from this survey was used for 
both 2014 and 2015 since it was the only coverage data available. Data were entered and analyzed using Microsoft Excel. This software was used because it is likely to be available and familiar to CMAM program managers. A Microsoft Excel spreadsheet that performs the required calculations is provided as online supporting material. All calculations were checked using the $R$ Language and Environment for Statistical Computing version 3.3.3 [28].

The method used to calculate the $95 \%$ confidence limits for the product of prevalence and coverage $(P C)$ is approximate. A less approximate $95 \%$ confidence interval (i.e. an interval that contains the true value close to $95 \%$ of the time) may be calculated using a bootstrap estimator $[29,30]$. Estimates of the incidence correction factor $(K)$ were made using a bootstrap estimator for the product of prevalence and coverage $(P C)$. A percentile bootstrap estimator with one million replicates for prevalence and coverage drawn from appropriate binomial distributions was used [29]. Data were analyzed using the $R$ Language and Environment for Statistical Computing version 3.3.3 [28].

\section{Results}

Table 2 shows the observed and expected (i.e. calculated using $K=1.6$ ) caseloads and the revised incidence correction factors $(K)$ for 2014 and 2015 together with the data on which the calculations were based. Use of $K=1.6$ to predict caseload had resulted in gross underestimates in both years. The resulting revised estimates for $K$ were $K=14.39$ (95\% CI $=6.64$; $30.02)$ and $K=11.66(95 \% \mathrm{CI}=5.94 ; 22.10)$ for 2014 and 2015 respectively. These estimates were pooled giving $K=13.02$ (95\% CI $=6.80 ; 19.25)$. The final two rows of Table 2 show the expected caseloads for 2014 and 2015 using the pooled estimate for $K$ and difference between the observed and expected caseloads. Table 3 compares estimates of the incidence correction factor $(K)$ calculated using the approximate method and the bootstrap estimator.

\section{Discussion}

The approach outlined in this document can provide useful estimates of locally appropriate incidence correction factors. Applying the value of $K$ estimated for 2014 to the population, prevalence, and coverage data for 2015 yields a predicted caseload of 484,766 cases. This is a $21.6 \%$ overestimate of the observed caseload for 2015. Some of this error may have been due to lower than specified coverage during the implementation phase of additional CMAM programming initiated in early 2015 as part of the ongoing emergency response in Northern Nigeria. This degree of error in caseload prediction is a considerable improvement

Table 2 Incidence correction factors for northern Nigeria CMAM program 2014 and 2015 and the data used to calculate them

\begin{tabular}{|c|c|c|c|c|}
\hline & & \multicolumn{2}{|l|}{ Year } & \multirow[b]{2}{*}{ Data sources } \\
\hline & & 2014 & 2015 & \\
\hline Population & N & $3,550,827$ & $4,281,700$ & $\begin{array}{l}\text { Nigeria census } 2006 \text { corrected for population growth } \\
\text { and migration. Population is for children aged between } \\
6 \text { and } 59 \text { months in districts in which CMAM services } \\
\text { were delivered. }\end{array}$ \\
\hline Prevalence $^{a}$ & $P$ & $1.60 \%(0.50 \% ; 2.71 \%)$ & $2.01 \%(0.82 \% ; 3.19 \%)$ & Pooled prevalence from state level SMART surveys \\
\hline Program Coverage $^{b}$ & C & $36.6 \%(32.3 \% ; 40.9 \%)$ & $36.6 \%(32.3 \% ; 40.9 \%)$ & Wide-area SLEAC survey \\
\hline Observed caseload & $L$ & 320,047 & 398,676 & Routine program monitoring data \\
\hline $\begin{array}{l}\text { Expected caseload } \\
\text { (using } K=1.6 \text { ) }\end{array}$ & $E_{K=1.6}=C N P(1+K)$ & 54,063 & 81,897 & $\begin{array}{l}C, N \text {, and } P \text { as above }(C \text { and } P \text { expressed as } \\
\text { proportions). Calculations are based on } K=1.6\end{array}$ \\
\hline $\begin{array}{l}\text { Difference (observed - } \\
\text { expected) }\end{array}$ & $L-E_{K=1.6}$ & 265,984 & 316,779 & $\begin{array}{l}\text { Calculated as the difference between observed } \\
\text { caseload }(L) \text { and expected caseload }(E) \text {. }\end{array}$ \\
\hline Prevalence $\times$ Coverage & $P C$ & $0.59 \%(0.29 \% ; 1.18 \%)$ & $0.74 \%(0.40 \% ; 1.34 \%)$ & Calculated (see text) \\
\hline $\begin{array}{l}\text { Incidence correction } \\
\text { factor }^{c}\end{array}$ & $K=\frac{L}{P C N}-1$ & $14.39(6.64 ; 30.02)$ & $11.66(5.94 ; 22.10)$ & Calculated (see text) \\
\hline $\begin{array}{l}\text { Expected caseload (using } \\
\text { pooled adjusted } \\
\text { incidence correction } \\
\text { factor) }\end{array}$ & $E_{K=13.02}=C N P(1+K)$ & 291,527 & 441,612 & $\begin{array}{l}C, N \text {, and } P \text { as above ( } C \text { and } P \text { expressed as } \\
\text { proportions). Calculations are based on } K=13.02 \text { (see } \\
\text { text). }\end{array}$ \\
\hline $\begin{array}{l}\text { Difference (observed - } \\
\text { expected) }\end{array}$ & $L-E_{K=13.02}$ & 28,520 & $-42,936$ & $\begin{array}{l}\text { Calculated as the difference between observed } \\
\text { caseload }(L) \text { and expected caseload }\left(E_{K}=13.02\right) \text {. }\end{array}$ \\
\hline
\end{tabular}

${ }^{a}$ Prevalence is for MUAC $<115 \mathrm{~mm}$ or bilateral pitting edema. This case-definition accounts for c. $98 \%$ of all program admissions based on an analysis of routine program monitoring data from two states of northern Nigeria ( $n=102,245$ admissions from January 2010 to December 2013 ). Prevalence estimates for the states in which the program was operating are reported. This was calculated as the population weighted average of SMART survey results from individual states

${ }^{b}$ Coverage refers to point coverage (i.e. the proportion of current SAM cases found by the survey that were enrolled in the CMAM program). Results from a wide-area SLEAC survey from February 2014 are used for both years [Banda et al., 2014]

${ }^{\mathrm{C}}$ The formula of the estimator for $K$ is rearranged to reflect the fact that PC was calculated prior to use 
Table 3 Estimates of the incidence correction factor made using two methods to calculate the product of prevalence and coverage

\begin{tabular}{lll}
\hline Year & K (approximate) & K (bootstrap) \\
\hline 2014 & $14.39(6.64 ; 30.02)$ & $14.72(7.73 ; 40.44)$ \\
2105 & $11.66(5.94 ; 22.10)$ & $11.91(6.17 ; 27.08)$ \\
Pooled & $13.02(6.80 ; 19.25)$ & $13.32(6.10 ; 20.53)$ \\
\hline
\end{tabular}

upon the $79.5 \%$ underestimate experienced when using $K=1.6$. Applying the pooled estimate of $K$ (i.e. $K=13.02$ ) to the population, prevalence, and coverage data yields predicted caseloads of 291,257 cases and 441,612 cases for 2014 and 2015 respectively. These are a 9.0\% underestimate and $10.8 \%$ overestimate of the true cases for 2014 and 2015. Error are likely to decrease over time as more annual estimates of $K$ become available. Not all errors have the same consequences. For example, overestimation may have positive consequences if program coverage is limited by stop-start funding and supply breaks caused by underestimation of burden and / or predicted caseload. Underestimation may lead to an under-resourced program in which program activities essential to achieving and maintaining coverage (e.g. community mobilization, community sensitization, and community-based case-finding activities) are neglected in order to maintain core clinical activities. Underestimation, in some cases, may lead to supply breaks necessitating the temporary closure of programs.

Confidence intervals for the bootstrap estimates of the incidence correction factors are wider than when the approximate method is used. Estimates made using the approximate method are likely to be spuriously precise. The use of approximate methods to calculate confidence intervals is, however, a widely accepted practice for many public health applications. The approximate method has the advantage of being easy to implement using software, such as Microsoft Excel, that is available and familiar to CMAM program managers.

Estimates of the incidence correction factor $(K)$ lack precision even when the approximate method is used. For example, the 95\% confidence interval for the 2015 estimate of the incidence correction factor $(K)$ using the approximate method ranges between $K=5.94$ and $K=22.10$. This translates into a $95 \%$ confidence interval for the caseload prediction of between about 218 thousand and 728 thousand. This degree of imprecision may limit the utility of the method as a planning tool.

The principal sources of imprecision are in estimates of prevalence and coverage. Improving the precision of estimates of prevalence and / or coverage will improve the precision with which the incidence correction factor $(K)$ is estimated.

SAM prevalence is usually estimated with poor relative precision. Relative precision of the prevalence estimates are $138 \%$ for the 2014 SAM prevalence estimate and $118 \%$ for the 2015 prevalence estimate. The lack of precision in prevalence estimates is due, in part, to the use of sample designs that reduce the effective sample sizes of surveys. It is likely that precision could be improved using, for example, stratified sample designs and larger sample sizes. This would, however, require considerable changes to current practice. Lack of precision is also due to the way that survey data are analyzed. Replacing the classic estimator:

$$
\text { Prevalence }=\frac{\text { Number of SAM cases found in the survey sample }}{\text { Survey sample size }}
$$

with a PROBIT estimator has been demonstrated to reduce the half-width of $95 \%$ CIs by about $60 \%$ with only small losses of accuracy [31-33]. Slightly Larger gains in precision have been demonstrated using a BayesianPROBIT estimator $[19,34]$. The advantage of data analytic approaches to improving precision are that they can be applied to data collected with currently used survey methods including historical data at little extra cost.

The precision of the coverage estimate was not an issue in the work reported here because a large stratified sample was used to estimate coverage with good relative precision (i.e. 23.5\%). Precision of coverage estimates may, however, be a problem for smaller programs. We investigated this issue using data from 227 SQUEAC coverage assessments of district-level NGO-delivered CMAM programs performed between January 2010 and July 2015 and provided to us by the Coverage Monitoring Network. The median relative precision for coverage estimates between $40 \%$ and $60 \%$ was $42.6 \%$ (IQR $=38.4 \%$; 48.5\%). This is an expected result as SQUEAC coverage assessments are usually designed to estimate coverage with this level of precision [12].

The poorer relative precision of SAM prevalence estimates means that efforts to improve the precision of these estimates are likely to yield greater improvements in the precision with which the incidence correction factor $(K)$ is estimated than may be achieved by efforts to improve the precision of coverage estimates. This is illustrated in Table 4 using the data from 2015. It is important to note that improvement in the precision of prevalence estimates can be achieved with very little increase in costs but that improvements in the precision of coverage estimates would entail considerable increases in costs.

\section{Limitations}

A key limitation of the work reported here is that coverage data was not current, particularly for 2015 .

A limitation of the method described here is that burden and caseload may be influenced by migration into and out of the program area. Rapid and substantial changes in the population of the program area are likely to affect 
Table 4 Effect of improved precision of SAM prevalence estimates and coverage estimates of the precision of the estimate of the incidence correction factor (K) using 2015 data from the Nigerian CMAM program

\begin{tabular}{|c|c|c|c|c|}
\hline \multirow[b]{2}{*}{ Scenario } & \multicolumn{4}{|c|}{ Incidence correction factor $(K)$} \\
\hline & Point estimate & $95 \% \mathrm{LCL}$ & $95 \%$ UCL & Relative precision ${ }^{a}$ \\
\hline No change & 11.66 & 5.94 & 22.10 & $139.59 \%$ \\
\hline Reduce half-width of $95 \% \mathrm{Cl}$ for prevalence by $60 \%{ }^{\mathrm{b}}$ & 11.66 & 7.72 & 17.37 & $82.76 \%$ \\
\hline Reduce half-width of $95 \% \mathrm{Cl}$ for coverage by $60 \%{ }^{\mathrm{c}}$ & 11.66 & 6.00 & 21.88 & $136.19 \%$ \\
\hline
\end{tabular}

${ }^{a}$ Relative precision is calculated as $\frac{95 \% \cup C L-95 \% L C L}{\text { Point Estimate }} \times 100$. Smaller values indicate better precision

${ }^{\mathrm{b}}$ This level of improvement is achievable using a PROBIT estimator with existing survey designs and survey data

'This level of improvement could only be achieved by a considerable increase in survey sample sizes

population size $(N)$, prevalence $(P)$, and program coverage $(C)$. Migration may, therefore, result in grossly inaccurate predictions of burden $(B)$ and caseload $(L)$ that are based on estimates of population size $(N)$, prevalence $(P)$, and program coverage $(C)$. Monitoring population movements and adjusting burden and caseload predictions may help to address this problem. Adjustment may also require that additional prevalence and coverage surveys be undertaken. In the case of the Nigerian CMAM program there have been reports of SAM cases entering Nigeria from Niger and being admitted to CMAM sites in districts that border Niger. The effect of this on the work reported here is likely to be small since data for the whole country were used. It is important to note that this may have larger effects on burden $(B)$ and caseload $(L)$ predictions for (e.g.) small NGOdelivered programs operating in border districts.

The assumption that caseload $(L)$ is measured with little or no error may also be a limitation. In the case of the Nigerian CMAM program there have been reports from 3 of the 114 districts in which the program is operating of beneficiaries being registered at more than one CMAM site with the assumed intention of receiving additional food and drugs. New CMAM sites were opened in these districts and some of the double registration may have been due to informal transfers between sites. An informal transfer would have been reported as a new admission at the destination site and, some weeks later, as a defaulting patient at the originating site. The effect of this would have been to increase reported caseload $(L)$. It seems likely that double registration will have had only a small effect on caseload $(L)$ used in the work reported here. This would have caused only a small increase in the estimates for $K$ reported here. The covert nature of some double registrations does mean that the magnitude of any increase will always be difficult to quantify.

\section{Conclusion}

The work reported here shows that it is possible to considerably improve predictions of CMAM caseload by applying a simple mathematical model to data that are readily available to program managers. This implies that more accurate predictions of burden may also be made using the same methods and data. The precision of estimates of caseload and burden may be improved by using PROBIT or Bayesian-PROBIT estimators of SAM prevalence.

The implication of this study, and of similar reports based on a variety of approaches (see Table 1), is that the current estimates of SAM burden are likely to be gross underestimates. Applying the pooled incidence correction factor found in this study to the 16 million estimate made using prevalence data yields an estimated global SAM burden of 208 (95\% CI = 109; 308) million cases annually. It seems unlikely, however, that the incidence correction factor estimated for the Nigerian CMAM program will be globally applicable. Local estimates of $K$ will be needed to make local prediction of burden and caseload. These local estimates of $K$ could be applied to local estimates of prevalence and population with the results summed in order to estimate global SAM burden.

Given the public health importance of having reliable estimates of burden and caseload and the uncertainties of this approach based on program data, a confirmation of estimates of $K$ using direct estimates of incidence from continuous monitoring of open cohorts and surveillance systems in similar settings may be warranted. Comparison with other indirect methods may also prove useful.

\section{Additional file}

Additional file 1: Caseload method. (XLSX $36 \mathrm{~kb})$

\begin{abstract}
Acknowledgements
The authors wish to thank Federal Ministry of Health of Nigeria for providing program data for the analysis.
\end{abstract}

Funding

No funding was obtained for this study.

Availability of data and materials

Data will be available upon request from the corresponding authors.

Authors' contributions

$A B, A B R, M M$ conceived the study and drafted the manuscript. All authors read and approved the final manuscript. 


\section{Ethics approval and consent to participate}

Not applicable.

\section{Consent for publication}

Not applicable.

\section{Competing interests}

The authors declare that they have no competing interests.

\section{Publisher's Note}

Springer Nature remains neutral with regard to jurisdictional claims in published maps and institutional affiliations.

\section{Author details}

${ }^{1}$ United Nations Children's Fund (UNICEF), Abuja, Nigeria. ${ }^{2}$ University of Tampere School of Medicine and Tampere University Hospital, University of Tampere, Center for Child Health Research, Lääkärinkatu 1, Arvo Building, Fl-33014 University of Tampere, Tampere, Finland. ${ }^{3}$ Department of Nutrition, Exercise and Sports, Faculty of Science, University of Copenhagen, Rolighedsvej 30, DK-1958 Frederiksberg, Denmark. ${ }^{4}$ United Nations Children's Fund (UNICEF), Nepal Country Office, UN House, Pulchowk, Lalitpur, Kathmandu, Nepal. ${ }^{5}$ Department of Family Health, Head of Nutrition/SUN Focal Point, Federal Ministry of Health, Abuja, Nigeria. 'Brixton Health, Alltgoch Uchaf, Llawryglyn, Powys, Wales SY17 5RJ, UK.

Received: 2 June 2017 Accepted: 28 September 2017 Published online: 09 November 2017

\section{References}

1. Anon, WHO child growth standards and the identification of severe acute malnutrition in infants: A joint statement by the World Health Organisation and the United Nations Children's Fund, WHO, Geneva, 2009.

2. Anon, Level and Trend in Acute Malnutrition, UNICEF / WHO / World Bank Group Joint Child Malnutrition Estimates: Key findings of the 2016 edition, Data and Analytics Section of the Division of Data, Research and Policy, UNICEF New York; the Department of Nutrition for Health and Development, WHO Geneva; and the Development Data Group of the World Bank, Washington DC, September 2016

3. Myatt M, Khara T, Collins S. A review of methods to detect cases of severely malnourished children in the community for their admission into communitybased therapeutic care programs. Food Nutr Bull. 2006;27(3):S7-S23.

4. Briend A, Collins S, Golden M, Manary M, Myatt M, Maternal and child nutrition, Lancet, November 2013:382(9904):1549.

5. Hure A, Oldmeadow C, Attia J. Invited commentary: improving estimates of severe acute malnutrition requires more data. Am J Epidemiol. 2016;184(12): 870-2.

6. Isanaka S, Grais RF, Briend A, Checchi F. Estimates of the duration of untreated acute malnutrition in children from Niger. Am J Epidemiol. 2011; 173(8):932-40

7. Glaser AN, High yield ${ }^{\text {TM }}$ biostatistics (3rd Ed.), Lippincott Williams \& Wilkins, Baltimore, Md., USA, 2005.

8. Myatt M. How do we estimate case load for SAM and / or MAM in children 6-59 months in a given time period? Llawryglyn: Brixton Health; 2012.

9. MacMahon B, Pugh TF. Epidemiology principles and methods. Boston, USA: Little Brown \& Company; 1970.

10. Golden M, Brennan M, Brennan R, Kaiser Rm, Colleen M, Nathan R, Robinson C, Woodruff B, Sean J, Erhardt J, Measuring Mortality, Nutritional Status, and Food Security in Crisis Situations: SMART METHODOLOGY (Version 1), CIDA / USAID / UNICEF, April 2006.

11. Clopper CJ, Pearson ES. The use of confidence or fiducial limits illustrated in the case of the binomial. Biometrika. 1934;26:404-13.

12. Myatt M, Guevarra E, Fieschi L, Norris A, Guerrero S, Schofield L, Jones D, Emru E, Sadler K. Semi-quantitative evaluation of access and coverage (SQUEAC) / simplified lot quality assurance evaluation of access and coverage (SLEAC) technical reference, food and nutritional technical assistance III project (FANTA-III), FHI 360 and FANTA. Washington, DC: FANTA; 2012. https://www.fantaproject.org/sites/ default/files/resources/SQUEAC-SLEAC-Technical-Reference-Oct2012_0. pdf.
13. Garenne M, Willie D, Maire B, Fontaine O, Eeckels R, Briend A, Van den Broeck J. Incidence and duration of severe wasting in two African populations. Public Health Nutr. 2009;12(11):1974-82.

14. Deconinck H, Pesonen A, Hallarou M, Gérar JC, Briend A, Donnen P, Macq J. Challenges of estimating the annual caseload of severe acute malnutrition: the case of Niger. PLoS One. 2016;11(9):1-13.

15. Isanaka S, Boundy EO, Grais RF, Myatt M, Briend A. Improving Estimates of Numbers of Children With Severe Acute Malnutrition Using Cohort and Survey Data, AJE. 2016;184(12)1-9.

16. Dale NM, Myatt M, Prudhon C, Briend A. Using cross-sectional surveys to estimate the number of severely malnourished children needing to be enrolled in specific treatment programmes. Public Health Nutr. 2017;24:1-5.

17. Aho KA, Bowyer RT. Confidence intervals for a product of proportions: application to importance values. Ecosphere. 2015;6(11):1-7.

18. Kish L. Survey sampling. New York: Wiley; 1965.

19. Raiffa H, Schlaifer R. Applied statistical decision theory. Cambridge: Division of Research, Graduate School of Business Administration, Harvard University; 1961.

20. Anon, Nigeria National Nutrition and health survey 2014, Nigeria National Bureau of Statistics, Abuja, Nigeria, 2014.

21. Anon, Nigeria National Nutrition and health survey 2015, Nigeria National Bureau of statistics, Abuja, Nigeria, 2015

22. Myatt M, Feleke T, Sadler K, Collins S. A field trial of a survey method for estimating the coverage of selective feeding programmes. Bull World Health Organ. 2006;83(1):20-6.

23. Aaron GJ, Sodani PR, Sankar R, Fairhurst J, Siling K, Guevarra E, Norris A, Myatt M. Household coverage of fortified staple food Commodities in Rajasthan, India. PLoS One. 2016;11(10):1-19.

24. Aaron GJ, Strutt N, Boateng NA, Guevarra E, Siling K, Norris A, Ghosh S, Nyamikeh M, Attiogbe A, Burns R, Foriwa E, Toride Y, Kitamura A, TanoDebrah K, Sarpong D, Myatt M. Assessing program coverage of two approaches to distributing a complementary feeding supplement to infants and young children in Ghana. PLoS One. 2016;11(10):1-19.

25. Anon, 2006 Population and housing census of the Federal Republic of Nigeria, Nigeria National Population Commission, Abuja, Nigeria, 2009

26. Banda C, Shaba B, Balegamire S, Sogoba M, Guevarra E, Fieschi L, Simplified Lot Quality Assurance Sampling Evaluation of Access and Coverage (SLEAC) Survey of Community Management of Acute Malnutrition program, Northern States of Nigeria, VALID International, Oxford, UK, 2014.

27. Guevarra E, Guerrero S, Myatt M. Using SLEAC as a wide-area survey method. Field Exchange. 2012;42:39-44.

28. R Code Team, R: a language and environment for statistical computing, $R$ Foundation for Statistical Computing, Vienna, Austria, 2017.

29. Efron B. Tibshirani, an introduction to the bootstrap. London: Chapman \& Hall; 1993.

30. Carpenter J, Bithell J. Bootstrap confidence intervals: when, which, what? A practical guide for medical statisticians. Stat Med. 2000 May 15;19(9):1141-64.

31. World Health Organization. WHO technical report series 854. Physical status: the use and interpretation of anthropometry. Report of a WHO expert committee. Geneva: World Health Organization; 1995.

32. Dale NM, Myatt M, Prudhon C, Briend A. Assessment of the PROBIT approach for estimating the prevalence of global, moderate and severe acute malnutrition from population surveys. Public Health Nutr. 2013 May;16(5):858-63.

33. Blanton CJ, Bilukha OO. The PROBIT approach in estimating the prevalence of wasting: revisiting bias and precision. Emerg Themes Epidemiol. 2013;10(1):8.

34. Altmann M, Fermanian C, Jiao B, Altare C, Loada M, Myatt M. Nutrition surveillance using a small open cohort: experience from Burkina Faso. Emerg Themes Epidemiol. 2016;13(1):745. 